\title{
Surface Modification of Polymeric Materials by Plasma Treatment
}

\author{
E.F. Castro Vidaurre ${ }^{* a}$, C.A. Achete ${ }^{\mathrm{b}}$, F. Gallo ${ }^{\mathrm{b}}$, D. Garcia $^{\mathrm{c}}$, R. Simão ${ }^{\mathrm{b}}$, \\ A.C. Habert ${ }^{\mathrm{C}}$ \\ ${ }^{a}$ Instituto de Investigaciones para la Industria Química, INIQUI-UNSa.-CONICET, \\ Universidad Nacional de Salta, 177-4400 Buenos Aires, Salta - Salta, Argentina \\ ${ }^{\mathrm{b}}$ Programa de Engenharia Metalúrgica e de Materiais, COPPE, Universidade Federal \\ do Rio de Janeiro, C.P. 68505 21945-970 Rio de Janeiro - RJ, Brazil \\ ${ }^{\mathrm{c}}$ Programa de Engenharia Química, COPPE, Universidade Federal do Rio de Janeiro \\ C.P. 68502 21945-970 Rio de Janeiro - RJ, Brazil
}

Received: November 13, 2000; Revised: December 29, 2001

\begin{abstract}
Low-temperature plasma treatment has been used in the last years as a useful tool to modify the surface properties of different materials, in special of polymers. In the present work low temperature plasma was used to treat the surface of asymmetric porous substrates of polysulfone (PSf) membranes. The main purpose of this work was to study the influence of the exposure time and the power supplied to argon plasma on the permeability properties of the membranes. Three rf power levels, respectively 5, 10 and $15 \mathrm{~W}$ were used. Treatment time ranged from 1 to $50 \mathrm{~min}$. Reduction of single gas permeability was observed with Ar plasma treatments at low energy bombardment $(5 \mathrm{~W})$ and short exposure time $(20 \mathrm{~min})$. Higher power and/or higher plasma exposition time causes a degradation process begins. The chemical and structural characterization of the membranes before and after the surface modification was done by AFM, SEM and XPS.
\end{abstract}

Keywords: membrane, polysulfone, plasma treatment, gas permeation

\section{Introduction}

Ion beam surface modification has shown great potential for improving surface properties of polymeric materials. As a result, the past few years have seen many advances in the field of ion beam surface modification of polymeric materials $^{1-4}$.

Notwithstanding the fact that ion implantation has long been a proven technology to modify surface properties of metals and semiconductors as well as ceramics, only in recent years have great efforts have been made in the surface modification of polymers by means of ion implantation technology. Indeed, surface properties can be more effectively modified by implantation for polymers than for any other materials, once the bond strength of polymers is much lower than that of metals, ceramics or semiconductors. So that the energy transferred to electrons by incoming ions can stimulate chemical reactions.

It is well known that the surface wettability and adhesion of polymers can be significantly improved by plasma treatment with non-polymer-forming gases. These treat-

*e-mail: elza@unsa.edu.ar

Trabalho apresentado no $14^{\circ}$ CBECIMAT, Águas de São Pedro, Dezembro de 2000 ments lead to the formation of radicals ${ }^{5}$ that are the promoters of surface cross-linking, functionalization, and degradation $^{3}$.

Argon is the most common inert gas used in plasma technology 6 . One of the major uses of Ar plasmas is in sputtering processes used in the semiconductor industry, pretreatment of substrates for cleaning purposes, and to improve the adhesive characteristics of polymers. An inert gas can also serve as a diluent or in the treatment known as CASING $^{7}$ (cross-linking by activated species of inert gases).

The capability of plasmas to alter surface physical and chemical properties without affecting the bulk properties of the base material is advantageous in several cases ${ }^{8-10}$. Either surface modification or thin-film deposition can create specific surface chemistries for optimization of membranes performance in separation process ${ }^{11}$.

Polysulfone (PSf) is one of the most frequently used polymers in the production of microfiltration and ultrafiltration membranes due to its mechanical, chemical and thermal high resistance, as well as its excellent film-form- 
ing properties. On the other hand, polysulfone membranes themselves are often used as sublayers in composite membranes for reverse osmosis, gas separation and pervaporation $^{11}$.

Hydrophilicity of polysulfone has already been improved in several investigations through application of chemical modification methods ${ }^{12}$ and plasma modified film ${ }^{3,12,8}$. The aim of this paper is to show how argon and ammonia plasma treatment alters the gas permeability, the and surface structure and the composition of porous polysulfone membranes.

\section{Experimental Procedures}

Commercial polysulfone (PSf) ultrafiltration membranes, with 10,000 Dalton cutoff, purchased from Danish Separation Systems AS were used.

The membranes were plasma treated in a glow discharge produced in a glass chamber fitted with horizontal parallel-plates electrodes capacitively coupled of a Varian r.f. (13.56 MHz) diode sputtering system. Both electrodes were water-cooled and the substrates were placed on the upper cathode electrode. The power was varied between 5 watts and 15 watts. During plasma exposition the substrate temperature increased by less than $50{ }^{\circ} \mathrm{C}$. Before each treatment, the reaction chamber was evacuated to a base pressure lower than $2 \times 10^{-5}$ mbar. The gas flow was set at $15 \mathrm{~cm}^{3} / \mathrm{min}$, maintaining the final pressure of $8 \times 10^{-2}$ mbar. After that, the rf generator was turned on and the plasma treatment was performed at a constant level of $\mathrm{rf}$ power for time ranging from $30 \mathrm{sec}$ to $50 \mathrm{~min}$.

The permeation measurements were performed in stationary mode in a conventional permeation cell coupled to a flowmeter and a pressure transducer. The experimental procedure is described elsewhere ${ }^{13}$. The permeation rate of gases through the membranes was measured at room temperature with pressure differences between the upstream and the downstream sides in the range 8.0-16.0 x $10^{4} \mathrm{~Pa}$, according to ASTM D143V. $\mathrm{N}_{2}(99.99 \%)$ and $\mathrm{CO}_{2}$ $(99.99 \%)$ were used as the feed gases. As the results obtained with both gases $\left(\mathrm{N}_{2}\right.$ and $\left.\mathrm{CO}_{2}\right)$ are very similar, we will present in this work, as a matter of simplification, only the values of permeation obtained for nitrogen gas.

Among 100 samples of substrate membranes, 20 were selected with intrinsic permeability $(\mathrm{P} / \mathrm{l})$ range $c a .8$ to $9 \times 10^{-3} \mathrm{~cm}^{3}$ (STP) $/ \mathrm{cm}^{2}$.s.cm Hg.

In order to control the nitrogen incorporation and the oxygen uptake after plasma exposition, surface composition (in wt. \%) of both treated and non-treated membranes were determined by means of X-Ray Photoelectron Spectroscopy (XPS). Spectra were recorded using a Perkin Elmer Spectrometer, PHI 1257, XPS Research System, with $\mathrm{MgK} \alpha$ radiation of $1253.6 \mathrm{eV}$ at a power of $200 \mathrm{~W}$ $(15 \mathrm{kV}, 2.0 \mu \mathrm{A})$.

AFM measurements were performed in an Accurex IIL from Topometrix in non-contact mode. In order to ensure that no measurable surface destruction occurred during the measurements a small area were was scanned for more then $30 \mathrm{~min}$ and then controlled scanning a larger area. Differences in the membrane surface morphology can be expressed in terms of mean roughness $\left(R_{a}\right)$. This parameter represents the mean value of the surface relative to the center plane, the plane for which the volumes enclosed by the image above and below this plane it are equal. This roughness parameter is calculated from the AFM images using an AFM software program.

\section{Results and Discussions}

Figure 1 shows the morphology of the cross-section of the asymmetric PSf as observed through with scanning electron microscope (SEM). The membrane is composed by a very thin skin with very small porosity. The porosity of the membrane grows very quickly within the depth sharply toward the membrane depth.

Figure 2 shows the AFM image of the top layer of the PSf membrane at $1 \mu \mathrm{m}$ scan range before plasma treatment. This figure shows a very smooth surface with typical nodular structure and interconnected cavity channels between the agglomerated nodules. The first direct evidence for what are now believed to be macromolecular aggregates in the skins of asymmetric membranes was found in cellulose acetate RO membranes by Schultz and Asunmaa. They called these structures "spheres". Recently, similar spherical structures have been observed in the skins of polysulfone gas separation membranes by Fritzsche et al. ${ }^{14}$ and Kim et al. ${ }^{15}$.

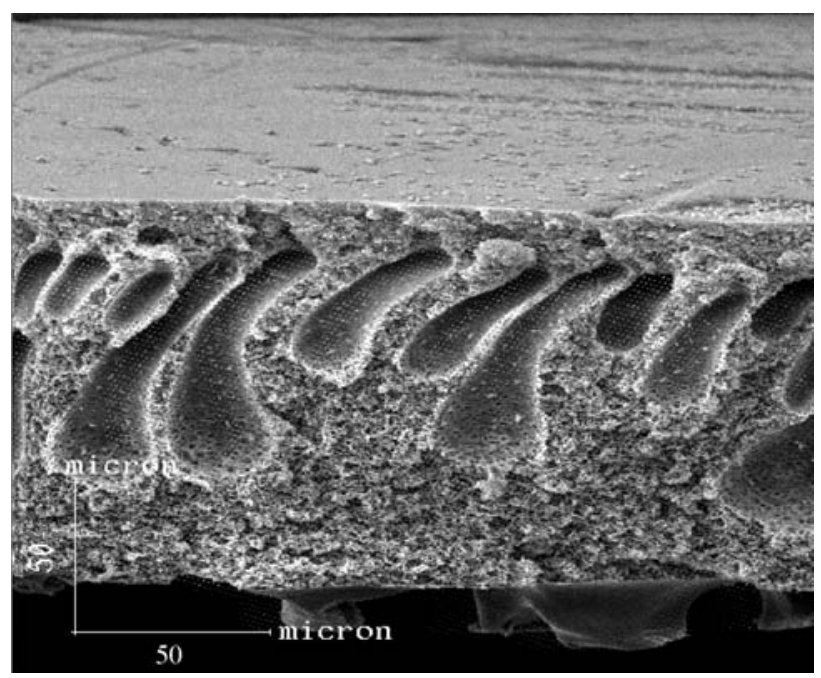

Figure 1. Scanning electron micrograph of cross-section of the asymmetric PSf membrane. 


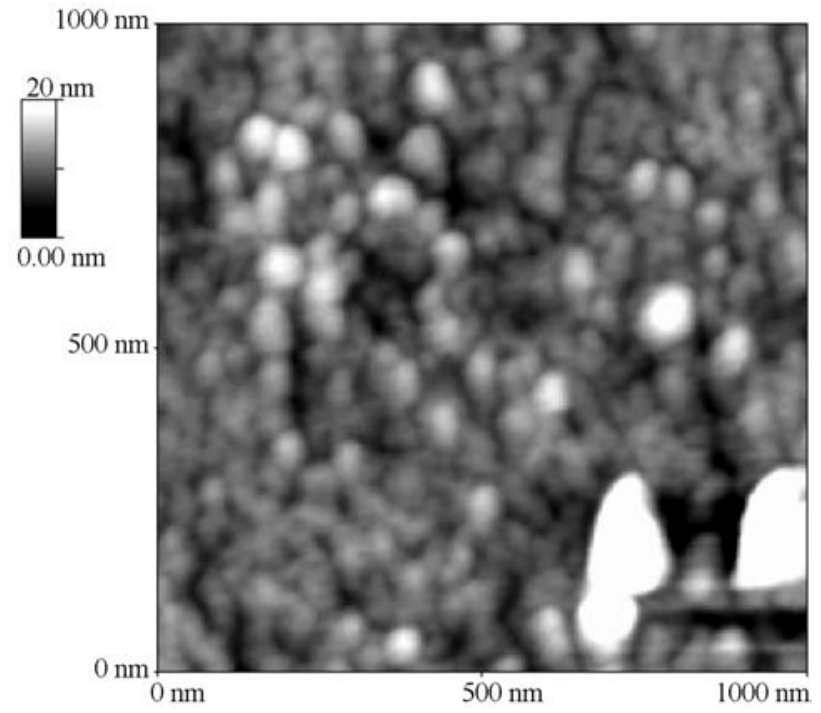

Figure 2. AFM image of the top surface of the PSf asymmetric ultrafiltration membrane (substrate). $\mathrm{R}_{\mathrm{a}}=1.6 \mathrm{~nm}$.

Figure 3 shows the permeation results obtained for the PSf membranes submitted to argon plasma treatment produced with $5 \mathrm{~W}$ of $\mathrm{rf}$ power. One can see that the permeability values decrease continuously up to $20 \mathrm{~min}$ of treatment, increasing again for longer times. The lowest value corresponds to a reduction of more than $30 \%$ of the permeability obtained for the untreated samples. This is evidence that the pores at the outmost surface of the membrane are being closed in some way during plasma exposition in the first stages of treatment. The most accepted explanation for this effect is the cross-linking of the polymer surface induced by the argon bombardment ${ }^{5}$. In order to get more insight about the surface changes induced by the ion bombardment, AFM measurements were carried out on samples treated under different conditions. Figure 4 shows the AFM topography of a membrane treated for $10 \mathrm{~min}$ at $5 \mathrm{~W}\left(\mathrm{R}_{\mathrm{a}}=1.2 \mathrm{~nm}\right)$. Comparing with the un-

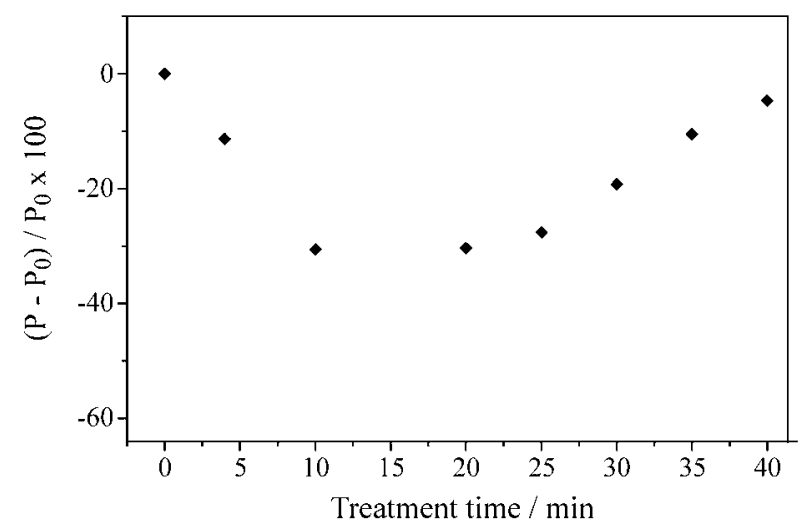

Figure 3. Nitrogen percentual variation permeability through ultrafiltration PSf membranes after argon plasma treatment, at $5 \mathrm{~W}$.

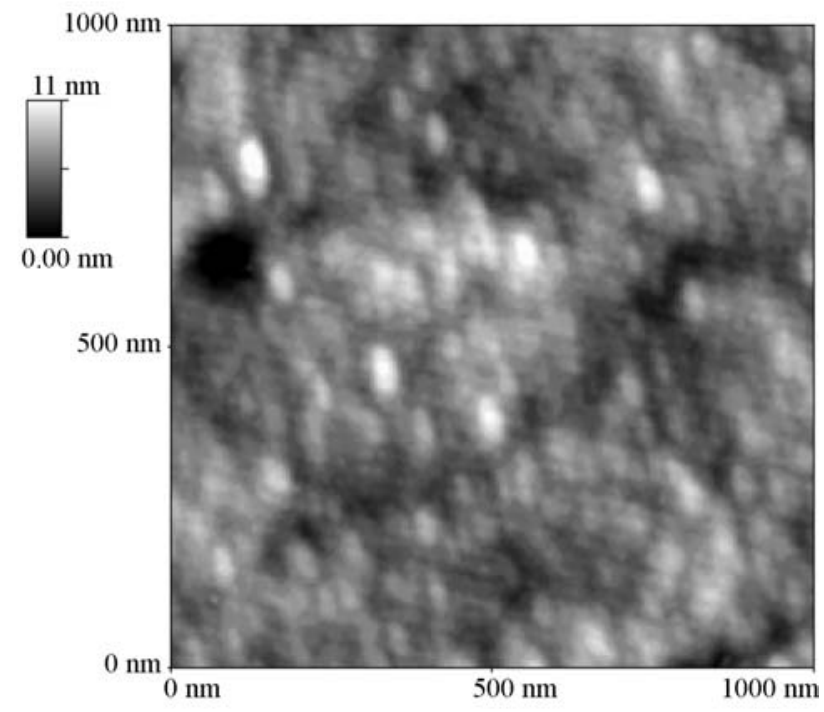

Figure 4. AFM image of the top surface of the PSf modified by argon plasma, $5 \mathrm{~W}, 10 \mathrm{~min} . \mathrm{R}_{\mathrm{a}}=1.2 \mathrm{~nm}$.

treated sample presented in Fig. $2\left(\mathrm{R}_{\mathrm{a}}=1.6 \mathrm{~nm}\right)$ one can see a remarkable reduction of the porous size after $10 \mathrm{~min}$ of argon treatment. Additionally to this densification of the external layers of the membrane there is a smoothing of the surface. This reduction in the roughness $\left(\mathrm{R}_{\mathrm{a}}\right)$ can be interpreted as a consequence of the reduction of the pores due to cross-linking. The polymeric chain "absorbs" free radicals by the formation of unsaturated carbon bonds and/or cross-linking. Shimomura et al. ${ }^{16}$ have demonstrated that PAN membranes Ar plasma-treated result in thin and insoluble layers when immersed in DMF (dimethylformamide), indicating that a certain number of cross-links were introduced by the plasma treatment.

Further exposure yields the formation of nodules (aggregates of molecules) as observed in Fig. 5, which shows topography of a sample treated at $5 \mathrm{~W}$ for $40 \mathrm{~min}$. These aggregates of molecules would be a result of an increase in the internal stress generated by successive cross-linking and as a consequence of this, large intermolecular spaces would be created. The permeability of gases was increased to about its original value for $40 \mathrm{~min}$ of exposure to $\mathrm{Ar}$ plasma. This result is similar to the ones found by Kramer and Yasuda ${ }^{6}$. Besides, a degradation process can begin to compete, because of the increase of temperature in ionic atmosphere, as Yasuda and Yasuda already proposed ${ }^{1}$. Some cracks begin to appear, indicating severe damage of the treated surface.

The permeability of gases was scarcely affected by the treatment with Ar plasma at $10 \mathrm{~W}$, as can be seen in Fig. 6. The permeability decrease was less than $20 \%$, indicating that the degradation process begin to appear at very shorts exposure. 


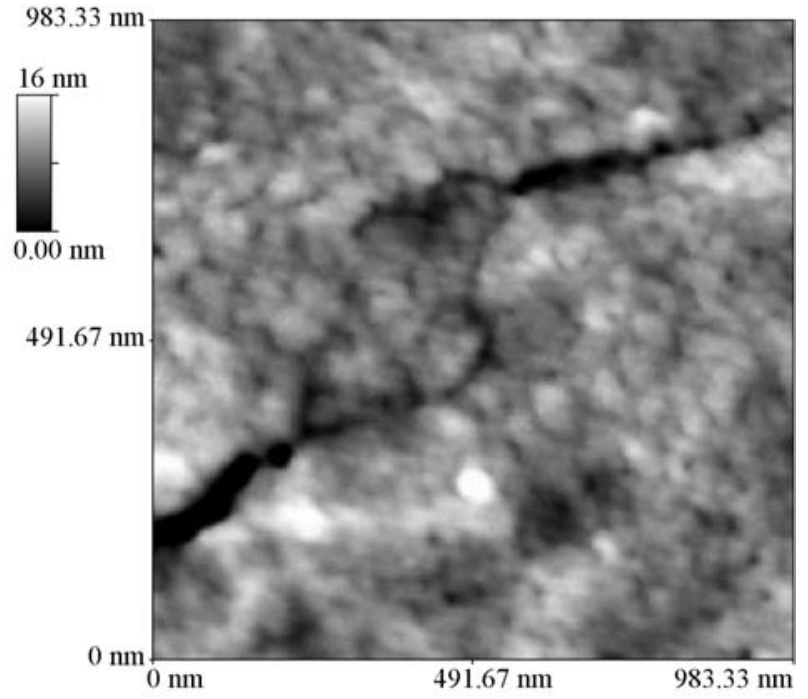

Figure 5. AFM image of the top surface of the PSf modified by argon plasma, $5 \mathrm{~W}, 40 \mathrm{~min} . \mathrm{R}_{\mathrm{a}}=2.0 \mathrm{~nm}$.

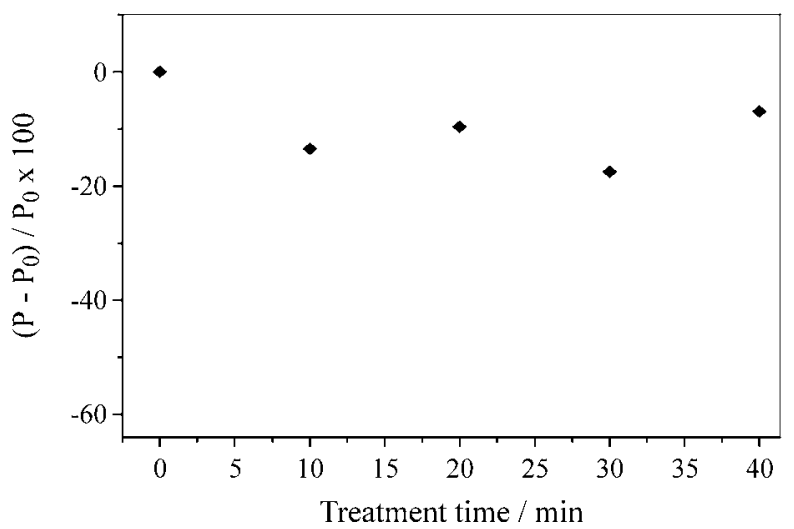

Figure 6. Nitrogen percentual variation permeability through ultrafiltration PSf membranes after argon plasma treatment, at $10 \mathrm{~W}$.

At power input of $15 \mathrm{~W}$, the permeability shows dispersion around the untreated membrane value, behavior similar to that observed for ammonia treatments ${ }^{17}$. As can be observed in AFM image of sample Ar- treated for $20 \mathrm{~min}$, $15 \mathrm{~W}\left(\mathrm{R}_{\mathrm{a}}=5.2 \mathrm{~nm}\right)$ (see Fig. 7), big nodules with large interstitial spaces are present on the surface and this could be the reason for the higher permeability. Khulbe and Matsuura observed similar results with increasing etching times in PPO membranes ${ }^{18}$.

Ablation begins to appear by rising the temperature and it occurs from little particles preferentially. Ablation and polymerization can occur in a competitive manner.

Nucleation and growth of fine particles into progressively larger particle aggregates takes place.

From XPS spectra, shown in Fig. 8 is evident that Ar is not incorporated in the PSf polymer surfaces (peaks at $\sim 260 \mathrm{eV}$ ). However, it is a common phenomenon that oxygen is incorporated on polymer surfaces after non-oxy-

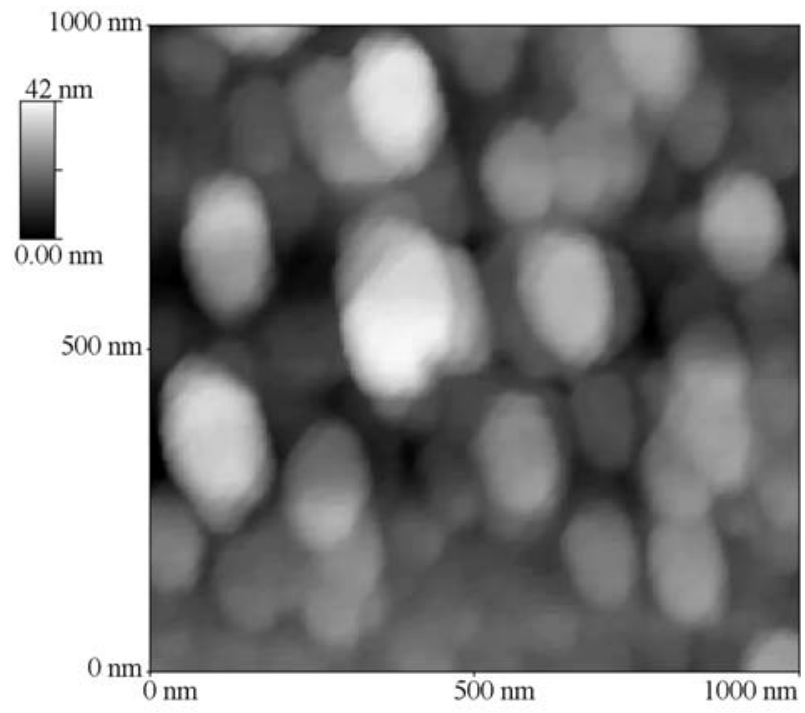

Figure 7. AFM top view images of the surface of the PSf modified by argon plasma, $15 \mathrm{~W}, 20 \mathrm{~min} . \mathrm{R}_{\mathrm{a}}=5.2 \mathrm{~nm}$.

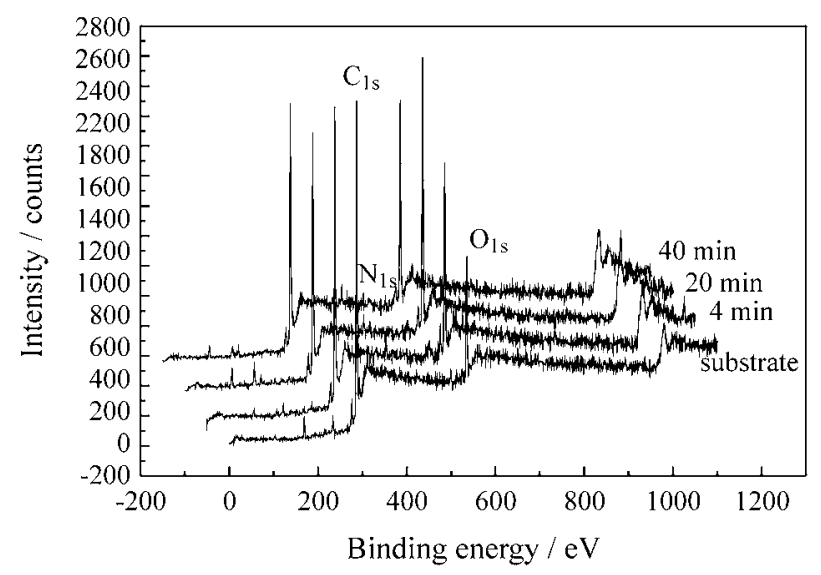

Figure 8. XPS survey scans of untreated and Ar treated membranes, during 4,20 and $40 \mathrm{~min}$ at $5 \mathrm{~W}$.

gen-plasma treatment, free radicals that are created on a polymer surface during o plasma treatment will react with oxygen when the surface is exposed to the atmosphere. Consequently, several hydrophilic groups on the polysulfone surface were introduced ${ }^{19-20}$.

\section{Conclusions}

Low power argon plasma is not so aggressive to the PSf surface and can lead to a reduction in gas permeation. It's possible to reduce the single gas permeability with surface layer compactation for Ar plasma treatment at low energy bombardment $(5 \mathrm{~W})$ and short exposure time $(20 \mathrm{~min})$. Higher power and/or higher plasma exposition time give rise to a degradation process.

The hydrophilic character of the modified surfaces was increased as compared to that of the parent membranes due 
to the oxygen incorporation when the membrane is exposed to the atmosphere.

\section{Acknowledgments}

The authors acknowledge financial support from, Pronex, Conselho Nacional de Desenvolvimento Científico e Tecnológico (CNPq) and Coordenação de Programas de Aperfeiçõamento de Pessoal de Nível Superior (CAPES). Thanks are also due to NUCAT (Núcleo de Catálise da COPPE/UFRJ) for the use of XPS results.

\section{References}

1. Yasuda, H.; Yasuda, T. Journal of Applied Polymer Science, v. 38, p. 943-950, 2000.

2. Inagaki, N.; Kubokawa, Y. Journal of Applied Polymer Science, v. 27, p. 795-805, 1989.

3. Gancarz, I.; Pozniak, G.; Bryjak, M.; Frankiewicz, A. Acta Polym., v. 50, p. 317-326, 1999.

4. Bhat, N.W.; Wavhal, D.S. Journal of Applied Polymer Science, v. 76, p. 258-265, 2000.

5. Kawakami, M.; Yamashita, Y.; Iwamoto, M.; Kagawa, S. Journal of Membrane Science, v. 19, p. 249-258, 1984.

6. Kramer, P.W.; Yeh, Y.S.; Yasuda, H. Journal of Membrane Science, v. 46, p. 1-28, 1989.

7. Inagaki, N. Plasma surface modification and plasma polymerization, Technomic publishing Co Inc., 1996.

8. Won, J.; Kim, M.H.; Kang, Y.S.; Park, H.Ch.; Kim, U.Y.; Choi, S.Ch.; Koh, S.K. Journal of Applied Polymer Science, v. 75, p. 1554-1560, 2000.
9.Lee, K.R.; Teng, M.Y.; Lee, H.H.; Lai, J.Y. Journal of Membrane Science, v. 164, p. 13-23, 2000.

10. Vasquez-Borucki, S.; Achete, C.A.; Jacob, W. Surface and Coatings Technology, in print.

11. Mulder, M. Basic Principles of Membrane Technology, Kluwer Academic Publishers, 1991.

12. Gancarz, I.; Pozniak, G.; Bryjak, M. European Polymer Journal, v. 36, p. 1419-1428, 1999.

13. Vasquez, S.; Achete, C.A.; Borges, C.P.; Franceschini, D.F.; Freire, F.L.; Zanghellini, Jr. E. Diamond and Related Materials, v. 6, p. 551-555, 1997.

14. Kesting, R.E. Journal of Applied Polymer Science, v. 41, p. 2739-2752, 1990.

15. Kim, J.Y.; Lee, H.K.; Kim, S.Ch. Journal of Membrane Science, v. 163, p. 159-166, 1999.

16. Shimomura, T.; Hirakawa, M.; Murase, I.; Sasaki, M.; Sano, T. Journal of Applied Polymer Science: Applied Polymer Symposium, v. 38, p. 173-183, 1984.

17. Castro Vidaurre, E.F.; Achete, C.A.; Simão, R.A.; Habert, A.C. Nuclear Instruments and Methods in Physics Research B, v. 175-177, p.732-736, 2001.

18. Khulbe, K.C.; Matsuura, T. Journal of Membrane Science, v. 171, p. 273-284, 2000.

19. Lin, J.Ch.; Cooper, S.L. Journal of Applied Polymer Science: Applied Polymer Symposium, v. 54, p. 157166, 1994.

20. Lin, Y.; Yasuda, H. Journal of Applied Polymer Science, v. 60, p. 2227-2238, 1996. 